\title{
IV. THE CALCIUM CONTENT OF MUSCLE.
}

\author{
BY CLARICE MARGARET BURNS. \\ From the Department of Physiology, University of Durham \\ College of Medicine.
}

(Received November 21st, 1932.)

THE facts that even excised muscle is sensitive to lack of calcium and that various forms of muscle tremors have been associated with low serum-calcium have led to the idea that changes may occur in muscle-calcium in various forms of tetany. The marked influence of diet on bone- and blood-calcium has suggested that muscle-calcium might also be similarly affected by this factor. Previous analyses of muscles have indicated a fairly wide range in the calcium content of normal muscle without showing any marked deviation from this average range under special conditions. Heubner and Rona [1923] failed to find any change in the calcium of dog muscle when the dogs received large doses of calcium chloride subcutaneously. Dennis and Corley [1925] failed to influence the calcium content of rabbit muscle by giving large doses of calcium lactate or chloride orally, with or without treatment by ultra-violet rays. Loughridge [1926] reported a drop in the muscle-calcium of dogs after parathyroidectomy. Dixon, Davenport and Ranson [1929] found on the other hand that the musclecalcium of a series of parathyroidectomised dogs fell within the same range as the muscle-calcium of a series of control animals. Haury [1930] found that the average calcium of the muscle of a batch of rachitic rats was lower by $40 \%$ than that of a batch of control animals given a similar diet to which phosphate had been added in sufficient quantity to prevent the development of rickets. Bülbring [1931] gave rats diets containing $0.86,0.46$ and $0.03 \%$ calcium. The muscle-calcium of rats on diets poor in calcium did not differ from that of those receiving $0.4 \%$ calcium, but the rats receiving the diet rich in calcium $(0.8 \%)$, which contained calcium lactate in addition to the ordinary salt mixture, showed a muscle-calcium generally higher than that of their litter-mates. On the two diets poorer in calcium, parathyroidectomy and parathormone injections produced no demonstrable consistent changes in muscle-calcium, but on the diet rich in calcium, muscles from parathyroidectomised animals or from animals receiving parathormone injections were richer in calcium than those of littermates on the other diets. The figures shown by all these workers seem to indicate that normal muscle-calcium may vary from about 4 to $25 \mathrm{mg}$. per $100 \mathrm{~g}$. of fresh tissue.

Since, however, calcium metabolism is known to be largely influenced by the dietary conditions of the stock from which animals are taken, series of estimations of muscle-calcium were made on control rats and also on their litter-mates kept under varying conditions. It was hoped in this way to demonstrate small changes which might be concealed by large differences among the controls taken at random from unknown stocks, as in most of the experiments referred to. 


\section{EXPERIMENTAL.}

Wistar Institute rats from the Glaxo laboratories were used, and the animals were kept in cages in groups of three or four and were fed their diets ad lib. Those receiving special doses of food were removed individually from the cages for this purpose. As far as possible, litters were equally distributed through the experimental groups, and all experimental animals were always compared with their litter-mate controls in interpreting the results. The animals were killed by bleeding from the neck.

The analyses were carried out (except where otherwise stated) on the thigh muscles, which were dried in silica crucibles and then ignited and extracted with $5 \% \mathrm{HCl}$. The filtrate from this extraction was made alkaline to methyl red with ammonia and then just acid with glacial acetic acid, and the calcium was precipitated as oxalate, using large excess of oxalate for the purpose. At least 24 hours had to be allowed for the complete precipitation of the calcium oxalate. The muscle ash was frequently found to be contaminated with silica from the crucibles, and repeated extraction of the ash was necessary to remove all the calcium. This was a potential source of serious error. A large number of control analyses were however carried out, which indicated that the analyses were accurate to $\pm 5 \%$, except in the case of the rachitic or other small animals, where only small amounts of muscle were available for analysis, so that the final titration figure was so low that errors might amount to a maximum of $\pm 10 \%$. The results were all interpreted with these technical limitations in mind ${ }^{1}$.

The distribution of calcium in the muscles of the two sides of the same animal was first studied (Table I). For this purpose the muscles of the legs and strips

Table I.

Calcium in mg. per $100 \mathrm{~g}$. of fresh muscle.

\begin{tabular}{|c|c|c|c|c|c|c|c|c|c|c|c|c|}
\hline $\mathrm{R} \varepsilon$ & at $\ldots$ & 1 & 2 & 3 & 4 & 5 & 6 & 7 & 8 & 9 & 10 & Av. \\
\hline Hind-legs & $\begin{array}{l}\text { Right } \\
\text { Left }\end{array}$ & $\begin{array}{l}6 \cdot 0 \\
5 \cdot 7\end{array}$ & $\begin{array}{l}6 \cdot 4 \\
6 \cdot 5\end{array}$ & $\begin{array}{l}7 \cdot 0 \\
8 \cdot 5\end{array}$ & $\begin{array}{l}6 \cdot 5 \\
5 \cdot 6\end{array}$ & $\begin{array}{l}6 \cdot 2 \\
5 \cdot 8\end{array}$ & $\begin{array}{l}6 \cdot 0 \\
7 \cdot 3\end{array}$ & $\begin{array}{l}7 \cdot 5 \\
8 \cdot 8\end{array}$ & $\begin{array}{l}5 \cdot 5 \\
8 \cdot 1\end{array}$ & $\begin{array}{l}6 \cdot 0 \\
8 \cdot 5\end{array}$ & $\begin{array}{l}6 \cdot 8 \\
5 \cdot 9\end{array}$ & $\begin{array}{l}6 \cdot 4 \\
7 \cdot 0\end{array}$ \\
\hline Fore-legs & $\begin{array}{l}\text { Right } \\
\text { Left }\end{array}$ & $\begin{array}{l}9 \cdot 0 \\
8 \cdot 5\end{array}$ & $\begin{array}{l}10 \cdot 1 \\
10 \cdot 3\end{array}$ & $\begin{array}{r}9 \cdot 2 \\
18 \cdot 6\end{array}$ & - & $\begin{array}{l}9 \cdot 4 \\
8 \cdot 6\end{array}$ & $\begin{array}{r}11 \cdot 4 \\
9 \cdot 0\end{array}$ & $\begin{array}{l}13.9 \\
16.5\end{array}$ & - & $\begin{array}{r}10 \cdot 5 \\
8 \cdot 3\end{array}$ & $\begin{array}{l}8 \cdot 0 \\
7 \cdot 7\end{array}$ & $\begin{array}{l}10 \cdot 2 \\
10 \cdot 9\end{array}$ \\
\hline $\begin{array}{l}\text { Abdominal } \\
\text { and pectoral } \\
\text { muscles }\end{array}$ & $\begin{array}{l}\text { Right } \\
\text { Left }\end{array}$ & $\begin{array}{l}6 \cdot 4 \\
6 \cdot 4\end{array}$ & $\begin{array}{l}5 \cdot 9 \\
7 \cdot 7\end{array}$ & $\begin{array}{l}8 \cdot 4 \\
6 \cdot 4\end{array}$ & $\begin{array}{r}14 \cdot 0 \\
7 \cdot 2\end{array}$ & $\begin{array}{l}7 \cdot 2 \\
7 \cdot 3\end{array}$ & $\begin{array}{l}6 \cdot 6 \\
7 \cdot 1\end{array}$ & ${ }^{(10 \cdot 3)^{*}}$ & $\begin{array}{l}9 \cdot 2 \\
9 \cdot 0\end{array}$ & $\begin{array}{r}8 \cdot 1 \\
11 \cdot 3\end{array}$ & $\begin{array}{l}8 \cdot 0 \\
8 \cdot 4\end{array}$ & $\begin{array}{l}8 \cdot 2 \\
7 \cdot 9\end{array}$ \\
\hline
\end{tabular}

from abdominal and pectoral muscles on each side of the medial line were used. The analyses were carried out on muscles from 10 animals on stock diet $\mathrm{S}$ (see p. 24). Of the 27 pairs of muscles so examined, 12 varied from their mean by less than $\pm 5 \%, 18$ by less than $\pm 10 \%$, and 25 by less than $\pm 15 \%$. In two pairs, muscle from one side had a calcium content twice that of the muscle from the other side. These analyses were all carried out on small samples of chopped muscle, as the rest of the muscle was required for another investigation; under these conditions an error of $\pm 10 \%$ might be regarded as the limit of accuracy for the estimation as carried out.

1 The use of platinum crucibles facilitated the acid extraction of the ash and increased the accuracy of the analysis, but only one such crucible was available. This was used in each set of experiments, but the results so obtained did not differ consistently from those derived from the analyses in silica. 
The influence of the calcium phosphate and vitamin $D$ contents of the diet was studied in two experiments. For the first the following diets were used.

(1) Diet R. Steenbock and Black's diet 2965 [Steenbock and Blačk, 1925]; Ca $1.3 \%, \mathrm{P} 0.45 \%, \mathrm{Ca} / \mathrm{P}=3.0$.

(2) Diet $\mathrm{P}$, i.e. $\operatorname{diet} \mathrm{R}+3.5 \% \mathrm{KH}_{2} \mathrm{PO}_{4} ; \mathrm{Ca} 1.3 \%, \mathrm{P} 1.2 \%, \mathrm{Ca} / \mathrm{P}=1 \cdot 1$.

(3) Diet $\mathrm{R}+\mathrm{E}$, i.e. diet $\mathrm{R}+$ daily doses of ergosterol.

(4) Diet $\mathbf{P}+\mathbf{E}$, i.e. diet $\mathbf{P}+$ daily doses of ergosterol.

(5) Diet S. Steenbock's stock diet $+15 \%$ dried milk [Bethke, Steenbock and Nelson, 1923]; Ca 0.37\%, P 0.48 \%, Ca/P =0.73.

(6) Diet $\mathrm{S}+$ carbonate. $\mathrm{S}+1.5 \% \mathrm{CaCO}_{3}$; Ca $1 \cdot 1 \%, \mathrm{P} 0.51 \%, \mathrm{Ca} / \mathrm{P}=2 \cdot 1$.

(7) Diet $\mathrm{S}+$ phosphate ( $\mathrm{S}+2 \%$ calcium phosphate); Ca $1.08 \%, \mathrm{P} 0.92 \%$, $\mathrm{Ca} / \mathbf{P}=\mathbf{1} \cdot \mathbf{1}$.

Forty rats were divided between the first four groups, each group containing 5 males and 5 females. The animals were put on to the diets at the age of 25-28 days. The females were killed after 36 days and the males after 42 days on the diets.

Fifteen other rats left from the same litters were divided as evenly as possible as regards litters into three groups and were put at the age of 30 days on to diets $\mathrm{S}, \mathrm{S}+$ carbonate, and $\mathrm{S}+$ phosphate, on which they were kept for 49 days. The calcium contents of the muscles of all these groups are shown in Table II. To demonstrate the influence of these diets on general calcium metabolism, the average calcium content for the femora + tibiae of the rats in each group, and the serum-calcium as estimated on serum from the mixed bloods of all the rats in each group are also given.

\section{Table II.}

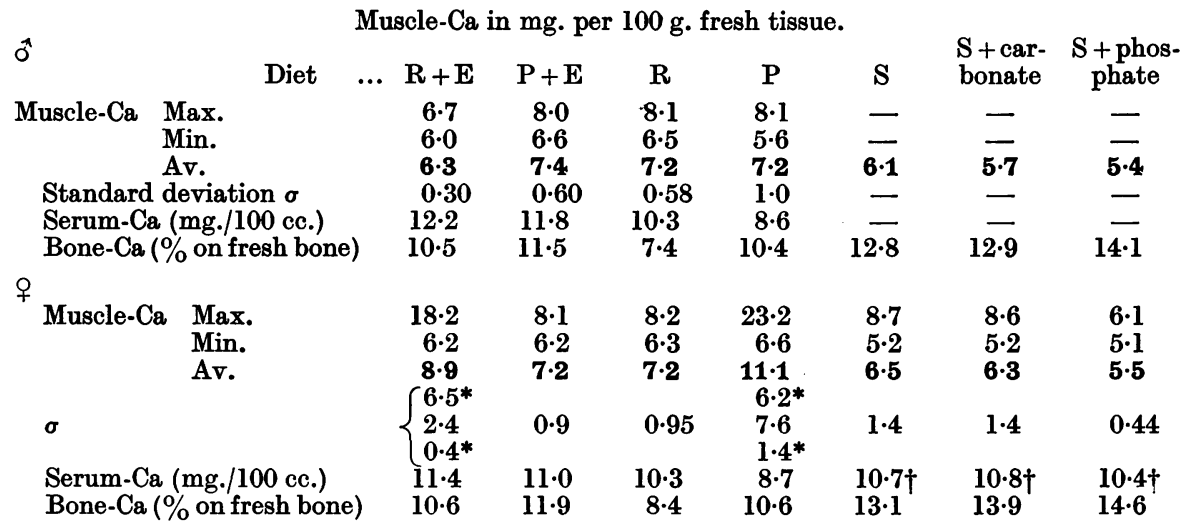

* Figures derived by excluding the one exceptionally high figure in the group.

$\dagger$ The 1 ot included in this group.

With the exception of one female on $\operatorname{diet} \mathbf{R}+\mathbf{E}$, with a muscle-calcium of 18.2, and two females on diet $P$ with muscle-calcium contents of $13 \cdot 6$ and $23 \cdot 2$, all the figures range from $5 \cdot 2$ to $8 \cdot 7$, and no significant difference is demonstrated between the sexes on the same diet, nor between animals on different diets, nor between animals aged 8 weeks ( + on $R, R+E, P$ and $P+E$ ) and animals from the same litter aged 11 weeks (우 on $S, S+$ carb. and $S+$ phosphate). Comparison of litter-mates also fails to show any consistent influence due to the diets. This is in marked contradistinction to the influence of the diets on 
bone-calcium, which is adequately indicated by the average percentages of bone-calcium, since only one of the 10 rats on diet $R$ had a bone-calcium which was not markedly less than that of all its litter-mates on other diets, while of the 10 rats on diet $\mathbf{P}+\mathbf{E}$ only one failed to exceed the bone-calcium of its litter-mates on diets $\mathrm{R}+\mathrm{E}$ and $\mathrm{P}$. The serum-calcium content as estimated on the pooled blood samples from the groups also seems to suggest an influence of the diet on serum-calcium.

These results fail to confirm Haury's finding that the muscle of rachitic rats contains less calcium than that of non-rachitic animals. This is equally true whether the comparison is made with a diet closely similar to the rachitic diet but containing vitamin $\mathbf{D}(\mathrm{R}+\mathrm{E})$, or containing enough phosphorus to give a $\mathrm{Ca} / \mathbf{P}$ ratio of $\mathbf{1}(\operatorname{diet} \mathbf{P})$, or with both these anti-rachitic conditions present $(\mathbf{P}+\mathbf{E})$, or on the other hand with a complete diet adequate in vitamins $(\mathbf{S})$, or with the modifications which give a high $\mathrm{Ca} / \mathrm{P}$ ratio or a normal $\mathrm{Ca} / \mathrm{P}$ ratio with high calcium and phosphorus.

The effect of vitamin D in ample quantity but not in excess was further studied by giving young rats the stock diet $\mathrm{S}$ and adding to the diet of one of each litter-mate pair a daily dose of irradiated ergosterol equal to ten times the quantity just necessary to give the line test in a rachitic animal in 3 days. This experiment was carried on for a period of 12 weeks, but was complicated by the fact that at the end of 8 weeks two animals died of pneumonia. The rest of the group showed loss of appetite for a day or two but rapidly became normal in appearance. Out of a total of 40 rats, however, only 7 continued to grow at a rate which could be regarded as normal, and at the end of 12 weeks they were all killed. At autopsy, one or two showed actual pus in the lungs, and most showed scarred lungs and calcareous deposits in the liver. Table III shows, however, that the muscle-calcium was unaffected by either the disease or the irradiated ergosterol in the quantity given. The number of litter-mate pairs which differ from their mean by less than $\pm 10 \%$ is $68 \%$ of the total, and all the pairs differ from their mean by less than $\pm 20 \%$.

Table III.

Muscle-Ca in mg. per $100 \mathrm{~g}$. fresh tissue.

$\begin{array}{ccccc} & & \text { No ergosterol } & \text { Ergosterol } & \mathrm{CaCl}_{2} \text { added } \\ \text { No. of animals } & \ldots & 16 & 12 & 10 \\ \text { Max. } & & \mathbf{7 \cdot 7} & \mathbf{7 \cdot 8} & \mathbf{8 . 5} \\ \text { Min. } & & \mathbf{5 \cdot 9} & \mathbf{5 \cdot 6} & \mathbf{5 6} \\ \text { Av. } & & \mathbf{6 \cdot 6} & \mathbf{6 \cdot 5} & \mathbf{6 \cdot 4} \\ \sigma & & \mathbf{0 \cdot 5 5} & \mathbf{0 . 7 1} & \mathbf{0 . 8 7}\end{array}$

Table III also shows the muscle-calcium content of rats which each received 1 cc. of $10 \% \mathrm{CaCl}_{2}$ solution mixed with their daily diet (which was the ordinary stock diet S). All the diet was not always consumed, but the animals grew well, indicating that they were taking an adequate amount. In this way they received a varying quantity of additional calcium daily in a soluble form. Only 10 rats were available at the time, and no litter-mates were kept on the ordinary diet, so that strictly the group cannot be compared with the others in Table VI. The results are however so similar to the others found for this breed of rat in all these experiments that it was considered justifiable to include them here.

The muscle-calcium of animals in which a state of hyperexcitability or active tetany had been induced by various means was next investigated. The methods used were $(a)$ the injection of guanidine salts, $(b)$ the feeding of phosphates or 
irradiated ergosterol to rachitic animals, $(c)$ parathyroidectomy. Muscles were examined from animals in varying stages of hyperexcitability. Batches of rats on stock diet $\mathrm{S}$ were given non-lethal doses of guanidine salts on alternate days. (Most rats tolerated a dose of $200 \mathrm{mg}$. of guanidine per $\mathrm{kg}$. of body weight, given intraperitoneally (I.P.) as lactate of $p_{H} 7 \cdot 0$.) On the days on which no guanidine was injected, the rats reacted similarly to animals in latent tetany and were slightly more excitable than their control mates. Guanidine group A (Table IV), shows the muscle-calcium values for these rats. In order to eliminate the effects of mere injection, when the experimental animals received guanidine, the controls received injections of equal quantities of normal saline, or of ammonium or of sodium salt solutions prepared so that the ammonium or sodium was molecularly equivalent to the guanidine.

About 1 to 3 hours after injection, the animals receiving guanidine usually showed great excitement, continuous face-washing and rapid breathing. This face-washing movement is frequently seen in normal rats, but is there extremely spasmodic and does not continue over a prolonged period as in the rats intoxicated with guanidine. Salvesen et al. [1924] report similar symptoms observed by them in parathyroidectomised dogs and in dogs in which they had induced tetany by the injection of large quantities of phosphates. When the dose of guanidine is non-lethal, the symptoms of irritation and the salivation gradually cease, and the breathing becomes normal. Group B (Table IV) shows the muscle-calcium values for rats killed in the condition of hyperexcitability.

A condition of hyperexcitability similar to that of rats 2 hours after a nonlethal dose of guanidine was produced in rachitic animals made rachitic on a diet with high $\mathrm{Ca} / \mathrm{P}$ ratio, by adding to the diet phosphate to give $\mathrm{Ca} / \mathrm{P}=1$, or irradiated ergosterol. After about 2 days, the healing of the bone lesions was found to be accompanied by a definite increase in the excitability of the animals, more rapid breathing and much face-washing. After a few hours these symptoms disappeared.

In another group, animals on stock diets were given a lethal dose of guanidine, and were killed usually when the intense face-washing, salivation and gasping indicated that the animals were on the verge of acute generalised tetany. (300 mg. of guanidine per kg. of body weight was usually enough to produce these symptoms in 1-2 hours if given I.P.) Group C (Table IV) gives the results of these experiments in which acute symptoms were produced.

Table IV.

$\mathrm{Ca}$ in mg. per $100 \mathrm{~g}$. fresh muscle.

\begin{tabular}{|c|c|c|c|c|c|c|c|}
\hline \multirow[b]{2}{*}{$\begin{array}{c}\text { Substance } \\
\text { injected }\end{array}$} & \multirow[b]{2}{*}{ None } & \multirow[b]{2}{*}{ Saline } & \multirow[b]{2}{*}{$\underset{\text { lactate }}{\text { Ammonium }}$} & \multirow[b]{2}{*}{$\begin{array}{r}\text { Sodium } \\
\text { lactate }\end{array}$} & \multicolumn{3}{|c|}{ Guanidine lactate } \\
\hline & & & & & $\mathbf{A}$ & B & $\overrightarrow{\mathrm{C}}$ \\
\hline $\begin{array}{l}\text { No. of rats... } \\
\text { Symptoms ... }\end{array}$ & $\begin{array}{c}10 \\
\text { None }\end{array}$ & $\begin{array}{c}5 \\
\text { None }\end{array}$ & $\begin{array}{c}5 \\
\text { None }\end{array}$ & $\begin{array}{c}15 \\
\text { None }\end{array}$ & $\begin{array}{c}7 \\
\text { Latent } \\
\text { tetany }\end{array}$ & $\begin{array}{c}9 \\
\text { Hyper- } \\
\text { excitability }\end{array}$ & $\begin{array}{c}9 \\
\text { Tetany }\end{array}$ \\
\hline $\begin{array}{l}\text { Max. } \\
\text { Min. } \\
\text { Av. } \\
\sigma\end{array}$ & $\begin{array}{l}8 \cdot 5 \\
5 \cdot 6 \\
6 \cdot 4 \\
0 \cdot 8\end{array}$ & $\begin{array}{c}- \\
5 \cdot 2^{*}\end{array}$ & $\frac{\bar{Z}}{5 \cdot \theta^{*}}$ & $\begin{array}{l}7 \cdot 2 \\
5 \cdot 4 \\
6 \cdot 4 \\
0 \cdot 54\end{array}$ & $\begin{array}{l}7 \cdot 8 \\
5 \cdot 9 \\
6 \cdot 4 \\
0 \cdot 66\end{array}$ & $\begin{array}{l}7 \cdot 7 \\
5 \cdot 6 \\
6 \cdot 7 \\
0 \cdot 70\end{array}$ & $\begin{array}{l}8.8 \\
6 \cdot 5 \\
7 \cdot 2 \\
1.07\end{array}$ \\
\hline
\end{tabular}

Table IV does not indicate any difference in the total muscle-calcium of rats according to the degree of hyperexcitability of the rat. 
In addition to inducing excitement in rachitic rats by dietary changes, tetany. was produced by injecting guanidine into rachitic rats which had received additional phosphate for 2 days (healing rickets) and into a small batch which had received irradiated ergosterol for 4 weeks (healed rickets). In both these groups active tetany was produced in 30-60 mins. by doses of $200 \mathrm{mg}$. guanidine per $\mathrm{kg}$. body weight, given I.P. In one or two animals half this dose sufficed to produce acute symptoms. It is not yet known whether this lack of resistance was a peculiarity of the group or was due to the diet.

Table $\mathrm{V}$ shows the results of the investigations on animals on rachitic diets.

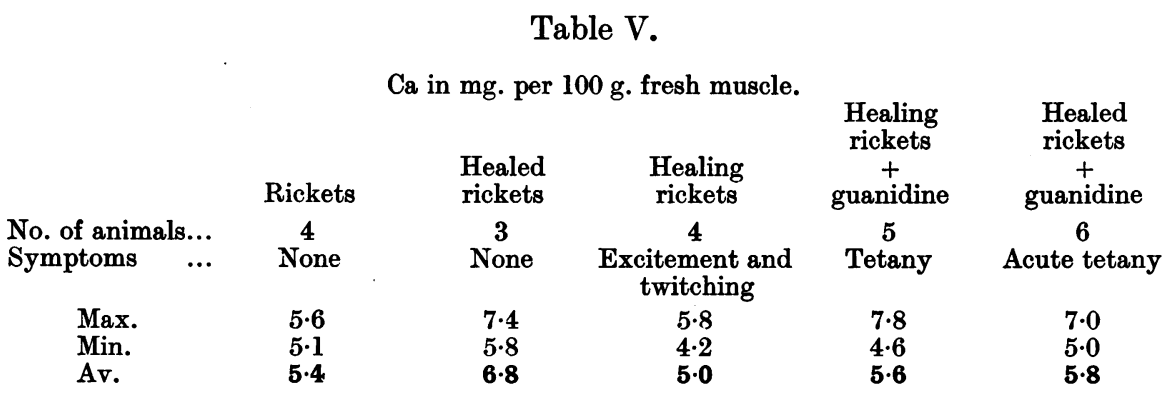

These figures do not differ significantly from each other or from those for the muscle of normal rats of this breed.

The influence of the injection of calcium chloride was demonstrated in one experiment in which 7 rats suddenly developed acute tetany after a dose of guanidine which they had been tolerating for some time. Their death was not desired at the time, and in an attempt to bring about their recovery $2 \mathrm{cc}$. of $10 \% \mathrm{CaCl}_{2}$ were injected into each animal I.P. The controls were similarly treated. A temporary improvement followed, but next morning five of the animals were found dead, and the other two were killed. The macroscopic appearance of the muscles of these animals was normal. Two days later littermates receiving saline were killed, and the following day controls to which ammonium lactate had been given were killed. In all the animals which survived more than 48 hours after the injection sores appeared round the site of injection, extending towards the hind-legs; the muscle still, however, appeared normal. The average values for the calcium contents of the muscles (mg. per $100 \mathrm{~g}$. fresh tissue) for the respective groups were guanidine $23 \cdot 3$, saline $13 \cdot 9$ and ammonium lactate 9.7. At first it seemed that these differences were due to the influence of the guanidine injections, but careful study of the individual figures showed that all the higher figures except one (and that in the saline group) were from animals killed within 48 hours of the calcium injection. The development of the sores indicated that some of the calcium solution had leaked into the tissues, and it seemed probable that some of this calcium had diffused into the muscle, from which its removal was slow, so that the animals first killed showed on the whole the higher content of muscle-caltium. It may be calculated that the presence in $5 \mathrm{~g}$. of muscle tissue of $0.07 \mathrm{cc}$. of the original injected calcium solution would suffice to raise the apparent calcium content of the muscle from 5 to $50 \mathrm{mg}$. per $100 \mathrm{~g}$. fresh tissue, without raising the water content beyond normal limits. The water content of these muscles did not in fact vary with the calcium. An experiment was, therefore, carried out in which 5 rats which had been receiving small doses of guanidine were given $500 \mathrm{mg}$. of guanidine per $\mathrm{kg}$. in $3 \mathrm{cc}$. of fluid I.P., and 1 hour later received $3 \mathrm{cc}$. of $5 \%$ 
$\mathrm{CaCl}_{2}$ solution, also I.P. A batch of controls was similarly treated except that sodium lactate was substituted for the guanidine. All these latter animals remained normal, but all those receiving guanidine developed symptoms of acute guanidine intoxication. The animals were killed 1 hour after the injection of the calcium chloride. The muscle-calcium values were as follows, for the sodium group $17 \cdot 2,18 \cdot 0,29 \cdot 1,29 \cdot 1,26 \cdot 3$, and for the litter-mates of the guanidine group $20 \cdot 6,30 \cdot 7,63 \cdot 3,10 \cdot 2$ and $9 \cdot 6$ respectively. None of these animals had a high value for liver-calcium, which would have indicated that the calcium had been carried there by the blood, and it seemed most probable that these high muscle-calcium figures could best be explained by leakage of the injected calcium into the surrounding tissues.

A small group of 8 rats was used to test the effect of parathormone injections on muscle-calcium. Six control rats had muscle-calcium values ranging from 5.9 to $9.4 \mathrm{mg}$. per $100 \mathrm{~g}$. fresh tissue with an average of $6 \cdot 9$, while 8 rats which received a total of 200 units of parathormone each in increasing doses over a period of 98 days had values ranging from 6.9 to $8 \cdot 2$, with an average of $7 \cdot 2$.

In none of these experiments on rats was muscle-calcium found to vary consistently from normal figures, except where calcium chloride solution had been injected into the peritoneum of animals which had already received intraperitoneal injections of considerable quantities of fluid. There is, moreover, no indication of any consistent difference from litter to litter. Nearly 200 rats were used altogether, but if from these are excluded all those which received calcium injections, and those in which the calcium estimations were done on the mixed muscle of several rats from different litters, there are left 138 estimations for the thigh muscles of rats from 23 litters. Of these 138, 3 are markedly different from the rest, viz. 13.6, 18.2 and $23.2 \mathrm{mg}$., and appear to have been influenced by some special factor. If they are arbitrarily excluded, and the average taken for the muscle-calcium of each litter, irrespective of the treatment which the animals have received, the following figures are derived.

Table VI.

\begin{tabular}{|c|c|c|c|c|c|c|c|c|c|}
\hline Litter & Average & Litter & Average & Litter & Average & Litter & Average & Litter & Average \\
\hline 1 & $7 \cdot 0$ & 6 & 6.5 & 11 & $6 \cdot 8$ & 16 & $7 \cdot 3$ & 21 & $8 \cdot 1$ \\
\hline 2 & $6 \cdot 7$ & 7 & $6 \cdot 3$ & 12 & $6 \cdot 2$ & 17 & $6 \cdot 7$ & 22 & $7 \cdot 6$ \\
\hline 3 & $7 \cdot 0$ & 8 & $6 \cdot 3$ & 13 & $6 \cdot 9$ & 18 & $6 \cdot 6$ & 23 & $7 \cdot 1$ \\
\hline 4 & $6 \cdot 7$ & 9 & $6 \cdot 4$ & 14 & $6 \cdot 8$ & 19 & $5 \cdot 6$ & & \\
\hline 5 & $6 \cdot 2$ & 10 & $6 \cdot 7$ & 15 & $6 \cdot 2$ & 20 & $5 \cdot 9$ & & \\
\hline
\end{tabular}

In Fig. 1 the distribution of the 138 estimations made on animals which received no injected calcium salts is indicated. The figure as a whole indicates that the greatest number of rats had a thigh muscle-calcium of from 6 to $6.5 \mathrm{mg}$. per $100 \mathrm{~g}$. fresh tissue, and that a large proportion of the total lay between 5-8 mg. with a few more and a few less than this range. By the shaded portions of the graph is indicated how this total was made up from the different groups. All rats were classed as normal which received a complete diet, grew well, had normal bones and blood and showed no pathological symptoms, whatever they were receiving as injection (i.e. saline, ammonium lactate, etc.). The figure shows that the muscle-calcium of these 55 animals was almost equally distributed between 5 and $7.5 \mathrm{mg}$., but that there were a few figures outside this range. The group classed as "prevented rickets" which included animals on diets $\mathbf{R}+\mathbf{E}, \mathbf{P}+\mathbf{E}$ and $\mathbf{P}$ are not included among normal animals as their growth was variable and on the whole poor, although their serum-calcium was normal, and bone calcification almost so. These 33 animals had a muscle-calcium range 
from 6-8 mg. with few cases greater and none less. (The three very high figures occur in this group.) The four small groups, tetany (20 rats), latent tetany (9 rats), excitement (13 rats) and rickets (13 rats) seem to be almost equally distributed over the whole range. This may be due to greater variability among animals under pathological conditions, or may merely result from the small number of animals in each group.

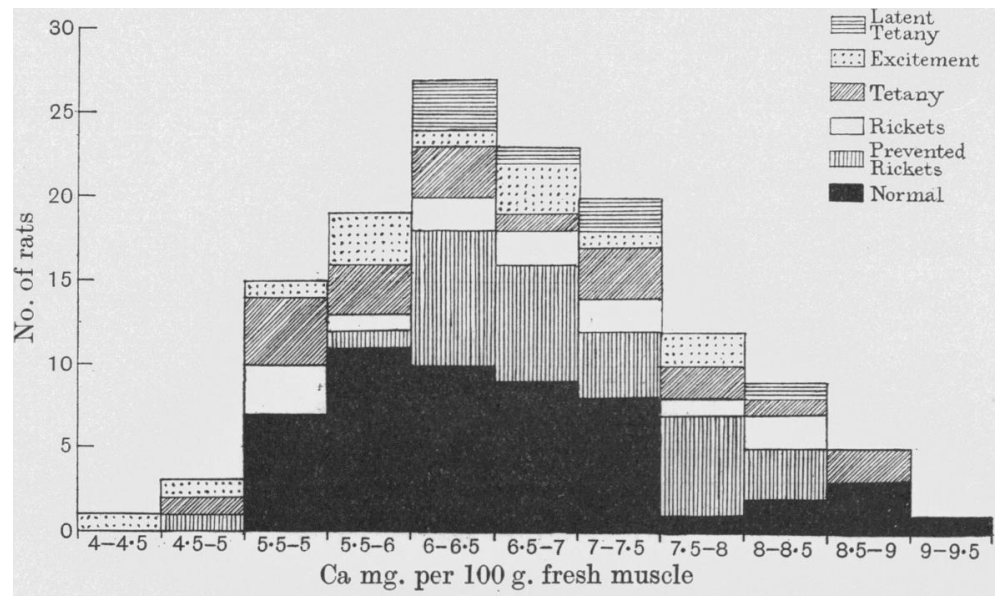

Fig. 1.

Dennis and Corley [1925] noted a similar variation in rabbit muscle and suggested as a probable cause the contamination of the muscle with lymph, blood, etc. Blood usually has a calcium content of 5-7 mg. per $100 \mathrm{cc}$. Two samples of fat from rats were examined for calcium and proved to contain 1-2 mg. per $100 \mathrm{~g}$. (The amount of fat available was too small to give the calcium more accurately.) Three samples of sheep tendon were analysed and the calcium found to be $8 \cdot 1,7 \cdot 5$ and $9 \cdot 4 \mathrm{mg}$. per $100 \mathrm{~g}$. fresh tissues. (It was assumed that the connective tissue of rats and sheep would probably contain the same order of calcium.) Nerve tissue (brain) of rats was found in agreement with Dennis and Corley (for rabbits) to contain calcium ranging from 8 to $16 \mathrm{mg}$. per $100 \mathrm{~g}$.

Now it may be calculated that if a muscle of actual calcium content of $8 \mathrm{mg}$. per $100 \mathrm{~g}$. was estimated to have only $5 \mathrm{mg}$. $/ 100 \mathrm{~g}$. of calcium because of the presence of fat containing $2 \mathrm{mg}$. per $100 \mathrm{~g}$. of calcium, the latter would need to be present to the extent of $50 \%$. Similarly if a muscle with actual calcium content of $5 \mathrm{mg}$. appeared to contain $8 \mathrm{mg}$. $/ 100 \mathrm{~g}$. because of contamination with nerve or connective tissue of a calcium content of $10 \mathrm{mg}$., then at least $60 \%$ of nerve or connective tissue would have to be present. Actually the animals were all bled from the neck and drained thoroughly, and all visible fat, blood-vessels and nerve tissue were removed. The tendons were cut off, but no attempt was made to remove the thin fibrous and closely adherent sheath of connective tissue. It would, however, seem improbable that the major variations in muscle-calcium were due to contamination with other soft tissues. The bone-calcium of the animals examined varied from 4 to $15 \%$ and contamination with a few $\mathrm{mg}$. of such bone would be enough to raise muscle-calcium to very high figures. To prevent such contamination, the muscles were removed with great care, and the layer of muscle next the bone was never included in 
the muscle for analysis. After dissection, all the muscle was carefully inspected through a hand lens. It would, therefore, seem more probable that the variations found in muscle-calcium represent real muscle differences rather than degrees of contamination.

\section{Experiments on animals other than rats.}

The difference between the calcium of the same muscle from opposite sides was studied in dogs, frogs and a cat. Muscles were taken in pairs from the two sides of dogs which had been used for blood-pressure measurements after small doses of guanidine, and the calcium was determined on each sample. A normal cat and three normal frogs were used in the same way (Table VII). Differences in the calcium contents of muscle from the two sides were here of the same order as had been previously noted for rats. The three samples of frog muscle examined were definitely richer in calcium than the muscle of the other species.

Table VII.

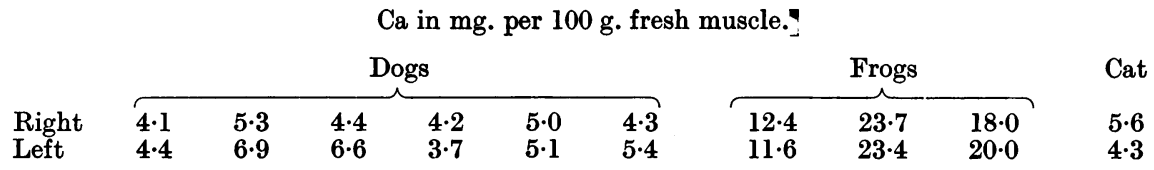

The effect of guanidine intoxication on rabbits was studied in two experiments. In the first, 6 rabbits were anaesthetised with ether, and the thigh muscles of one leg removed. $200 \mathrm{mg}$. of guanidine per $\mathrm{kg}$. of body weight were injected intravenously as lactate (adjusted to $p_{\mathrm{H}} \mathbf{7 \cdot 0}$ ), and at the end of 20 mins., when an unanaesthetised animal would have been in acute tetany, the similar muscle from the other leg was removed. Muscle-calcium before and after guanidine was determined (Table VIII).

Table VIII.

\begin{tabular}{|c|c|c|c|c|c|c|}
\hline \multicolumn{7}{|c|}{$\mathrm{Ca}$ in mg. per $100 \mathrm{~g}$. } \\
\hline Rabbit ... & I & II & III & IV & V & VI \\
\hline $\begin{array}{l}\text { Before } \\
\text { After }\end{array}$ & $\begin{array}{l}8 \cdot 3 \\
5 \cdot 0\end{array}$ & $\begin{array}{l}7.0 \\
6.0\end{array}$ & $\begin{array}{l}4 \cdot 7 \\
3 \cdot 6\end{array}$ & $\begin{array}{l}4 \cdot 2 \\
4 \cdot 3\end{array}$ & $\begin{array}{l}5 \cdot 2 \\
5 \cdot 0\end{array}$ & $\begin{array}{l}5 \cdot 8 \\
5 \cdot 0\end{array}$ \\
\hline
\end{tabular}

In the second experiment two litters of two and six respectively were used. One of the two rabbits was kept as control, and the other was given a dose of $300 \mathrm{mg}$. guanidine per $\mathrm{kg}$. of body weight. The guanidine solution was prepared by bringing a solution of guanidine carbonate to $p_{\mathrm{H}} 7.0$ with phosphoric acid. Three of the six were similarly injected with guanidine, one was kept as an uninjected control, and two received injections of sodium solutions prepared like the guanidine solution, so that the sodium was molecularly equivalent to the guanidine. At the end of 25 minutes all the four animals receiving guanidine were showing marked symptoms of tetany. At the end of 30 minutes, when all were in acute tetany and two were in opisthotonus, all the animals were killed. The two which received sodium were excited for a couple of minutes after the injection, then rapidly became normal. From 5 to 30 mins. after the injection they appeared perfectly well and normal and chewed fragments of hay that were lying about the cage. The calcium and solids of the serum and the calcium of the thigh muscles were determined for all these animals (Table IX). No consistent change was found in the muscle-calcium despite the violent muscular 
contractions. Serum-calcium is only definitely lowered as compared with control animals when total serum-solids are also appreciably lowered, and this may, therefore, only indicate dilution of the blood by the injected fluid. In rabbits, as in rats, there is nothing to correlate the increased muscular excitability typical of tetany with any change in the total calcium content of the muscle.

\begin{tabular}{|c|c|c|c|c|c|c|c|c|}
\hline & \multirow[b]{2}{*}{$\begin{array}{l}\text { Control } \\
\text { litter } a\end{array}$} & \multirow[b]{2}{*}{$\begin{array}{l}\text { Guani- } \\
\text { dine } a\end{array}$} & \multirow[b]{2}{*}{$\underset{b}{\text { Control }}$} & \multicolumn{2}{|c|}{ Sodium $b$} & \multicolumn{3}{|c|}{ Guanidine $b$} \\
\hline & & & & 1 & 2 & 1 & 2 & 3 \\
\hline $\begin{array}{l}\text { Serum-Ca } \\
\text { (mg. per } 100 \text { cc.) }\end{array}$ & $14 \cdot 4$ & $9 \cdot 2$ & $13 \cdot 7$ & $12 \cdot 1$ & $10 \cdot 0$ & $12 \cdot 5$ & $10 \cdot 4$ & $8 \cdot 0$ \\
\hline $\begin{array}{l}\text { Serum-solids } \\
\text { (g. per } 100 \text { cc.) }\end{array}$ & $8 \cdot 6$ & $6 \cdot 7$ & $8 \cdot 25$ & $8 \cdot 0$ & $8 \cdot 3$ & $8 \cdot 2$ & $7 \cdot 6$ & $6 \cdot 6$ \\
\hline $\begin{array}{l}\text { Muscle-Ca } \\
(\mathrm{mg} \text {. per } 100 \text { g.) }\end{array}$ & $4 \cdot 1$ & $3 \cdot 2$ & $3 \cdot 4$ & $3 \cdot 5$ & $3 \cdot 2$ & $3 \cdot 5$ & 3.4 & $4 \cdot 0$ \\
\hline
\end{tabular}

Parathyroidectomised kittens. The effect of parathyroidectomy on musclecalcium was studied in four litters of kittens. Total thyroparathyroidectomy was performed under ether; in each experiment, one kitten from the litter was used as a control and was anaesthetised, a skin incision made and the thyroid sheath split and manipulated as though the thyroid was to be removed. The animals were fed on milk after the operation. Four of the kittens so thyroparathyroidectomised showed marked tremors after $\mathbf{4 0}$ hours and developed a quite characteristic paw-shake, as though water was being shaken off the paws. One kitten, at this stage, suddenly developed acute tetany. All five were killed at this early stage. A sixth kitten survived for a week without showing any symptoms of tetany and seemed quite happy throughout. It was killed on the seventh day, and post mortem examination showed that the operation for the removal of thyroids and the customary parathyroids had been successful. No examination of other tissues for accessory parathyroids was made.

In the fourth litter, two kittens developed acute tetany within 16 hours and were killed. The third parathyroidectomised kitten showed no symptoms of tetany during the three days succeeding the operation, but was then killed.

Table X.

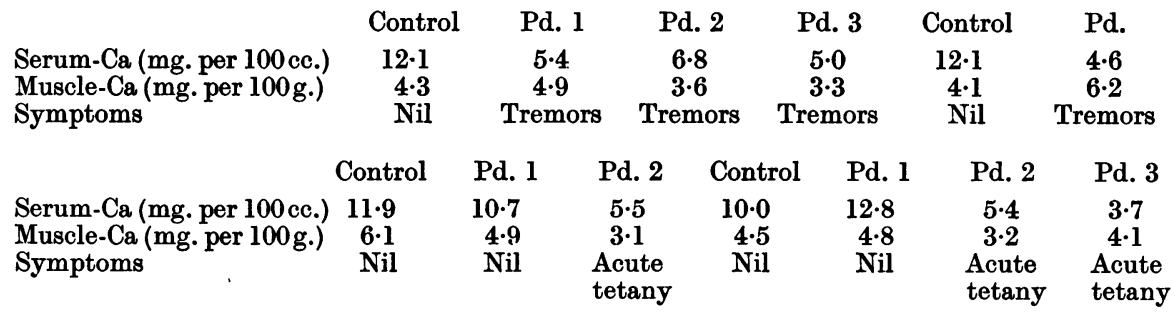

Table $\mathrm{X}$ shows that while serum-calcium at the time of death varies with the state of tetany of the animal, no such consistent variation is found in musclecalcium.

\section{Discussion.}

The experiments here described, on rats, cats and rabbits, broadly agree with the observations of Dennis and Corley [1925] that considerable variation may be met with in the normal muscle-calcium of animals, but that, at any 
rate when control animals are receiving a normal amount of calcium in their food (in this case $0.4 \%$ ), further increase in the calcium or vitamin $D$ of the diet does not increase muscle-calcium. The observations of Dixon, Davenport and Ranson [1929] on parathyroidectomised dogs are also confirmed on kittens. The results obtained, however, fail to confirm those of Haury [1930] on rachitic rats, or of Bülbring [1931] or of Loughridge [1926] on parathyroitlectomised animals. It would seem that the latter might have reached a different conclusion after more experiments, but the results of Haury and of Bülbring cannot be so explained. The fact, however, that some animals seem to have markedly higher muscle-calcium values than the others of their species suggests that in these animals some special condition obtains. All Haury's control rats fell into this group, and it may be significant that the three very high figures found in the above investigation for thigh muscle of rats were for animals on diets somewhat similar to that chosen by him for his control group: i.e. diets producing the condition described above as "prevented rickets." No adequate comparison can be made between Bülbring's parathyroidectomised rats and the parathyroidectomised kittens of these experiments. Bülbring maintained her animals over the stages of tetany by injecting calcium solutions, while the kittens were killed in the early stages of the first attack of tetany. No conclusion can be drawn from these experiments as to the storage of calcium in the body after parathyroidectomy, but they seem to show that the muscular contractions of tetany in kittens are not preceded by any significant change in total musclecalcium. This is also true of the tetany and muscular hyperirritability produced in rats and rabbits by guanidine intoxication or by the sudden induction of the healing processes in rachitic animals.

I wish to thank Mr A. L. Bacharach of the Glaxo Research Laboratory for the supply of irradiated ergosterol, and Prof. Burns and Dr Secker for parathyroidectomising the animals. The expenses of this research were defrayed by a grant to Prof. Burns from the Medical Research Council.

\section{REFERENCES.}

Bethke, Steenbock and Nelson (1923). J. Biol. Chem. 58, 71. Bülbring (1931). Arch. Exp. Path. Pharm. 162, 209. Dennis and Corley (1925). J. Biol. Chem. 66, 609. Dixon, Davenport and Ranson (1929). J. Biol. Chem. 83, 737. Haury (1930). J. Biol. Chem. 89, 467.

Heubner and Rona (1923). Biochem. Z. 135, 248.

Loughridge (1926). Brit. J. Exp. Path. 7, 302. 